\title{
Protective effects of berry polyphenols against age-related cognitive impairment
}

\author{
Julien Bensalem ${ }^{\mathrm{a}, \mathrm{b}, \mathrm{d}}$, Alexandre Dal-Pan ${ }^{\mathrm{e}, \mathrm{f}, \mathrm{g}}$, Elodie Gillard ${ }^{\mathrm{e}}$, Frédéric Calon ${ }^{\mathrm{e}, \mathrm{f}, \mathrm{g}}$ \\ and Véronique Pallet ${ }^{\mathrm{a}, \mathrm{b}, \mathrm{c}, \mathrm{g}, *}$ \\ ${ }^{a}$ Univ. de Bordeaux, Nutrition et neurobiologie intégrée, UMR 1286, 33000 Bordeaux, France \\ ${ }^{\mathrm{b}}$ INRA, Nutrition et neurobiologie intégrée, UMR 1286, 33000 Bordeaux, France \\ ${ }^{\mathrm{c}}$ Bordeaux INP, NutriNeuro, UMR 1286, F-33000, Bordeaux, France \\ dActiv'Inside, 33500 Libourne, France \\ ${ }^{\mathrm{e}}$ Faculté de Pharmacie, Université Laval, Centre de Recherche du CHU de Québec, Québec, Canada \\ ${ }^{\mathrm{f}}$ Institut des Nutraceutiques et des Aliments Fonctionnels, Université Laval, Québec, Canada \\ ${ }^{\mathrm{g}}$ OptiNutriBrain International Associated Laboratory (NutriNeuro France-INAF Canada), 33000 Bordeaux, \\ France
}

\begin{abstract}
A growing body of evidence suggests that dietary interventions may delay or halt the progression of age-related health disorders and cognitive decline. Among the components of the human diet, polyphenols from berries are essential micronutrients that have been particularly studied for improving cognitive functions. In the present review, we highlight the health impact of major polyphenolic classes found in berries: flavanols, anthocyanins and stilbenes, focusing on resveratrol. The reports of beneficial effects of berry consumption on age-related cognitive decline and associated neurobiological processes in animals and human are underscored. We then discuss the potential benefit of each category of polyphenols on memory impairment and in neurodegenerative diseases. Berry polyphenols improve several types of memory and have a global effect on brain plasticity, partly through their antioxidant activity and/or their effect on neuronal signal transduction and neuroinflammation. Interestingly, accumulated bioavailability data suggest that most polyphenols, or at least key metabolites, can access the brain in sufficient concentrations. Collectively, the data accumulated so far suggest that dietary polyphenols can modulate brain health and function, and strengthen the importance of fruit consumption for a healthy brain aging and the prevention of age-related diseases. However, further preclinical work is needed to determine the most neuroactive nutraceutical formulations, whether through the diet or supplement, to subsequently design and perform informative clinical trials.
\end{abstract}

Keywords: Polyphenols, flavonoids, flavanols, anthocyanins, resveratrol, berries, memory, plasticity, aging, neurodegenerative disease

\section{Introduction}

Old age is well known to be associated with cognitive impairment and neurodegenerative disorders such as Alzheimer's disease (AD) and Parkinson's

\footnotetext{
${ }^{*}$ Corresponding author: Véronique Pallet, Nutrition and Integrative Neurobiology, UMR 1286 INRA - Université de Bordeaux, Bâtiment UFR de Pharmacie $2^{\mathrm{e}}$ tranche, $2^{\mathrm{e}}$ étage, case courrier 34, 146 rue Léo Saignat, 33076 Bordeaux cedex, France. Tel.: +33 5575712 30; Fax: +33 5575712 27; E-mail: veronique.pallet@enscbp.fr.
}

disease (PD) [1]. As the elderly population increases, so will the prevalence of these age-related disorders [2-4]. In order to improve the quality of life of the elderly and to alleviate the social and economic burdens caused by dependence, it is important to develop strategies to reverse, or least minimize, age-related cognitive decline and delay the onset of neurodegenerative diseases. To this end, nutrition-based preventive strategies are currently being attempted to avoid or delay the evolution towards dementia and thus maintain a stable cognitive state and 
satisfactory wellness in elderly subjects. In recent years, we have observed an intensification of research dedicated to understanding the relationship between nutrition and "healthy aging". Among foods that are potentially capable of protecting against age-related degenerative diseases, fruits and vegetables rich in polyphenols have been put forward as possible tools to delay age-related physiological and functional deficits $[1,5,6]$.

Polyphenols, particularly flavonoids, have been shown to ameliorate learning and memory processes and are today extensively studied for their potential to prevent age-related cognitive decline in both animals [7-11] and humans [12-17]. Although the mechanisms of action of flavonoids remain unclear, there is evidence that they modulate cellular and molecular processes involved in learning and memory [18]. Among the different polyphenols found in berries, those which have been particularly studied for their effect on brain function are flavonoids-particularly flavanols and anthocyanins- and among the stilbene family, resveratrol. Other stilbenes are present in berries, but few or no data is available concerning their neuroactivity. Indeed, resveratrol is considered among the most potent biologically active nutrient. Initially studied for its presence in red wine and its link with the "French paradox" [19], resveratrol has been shown to partially mimic caloric restriction, to extend the lifespan and to improve cognitive function and delay age-related cognitive impairment [20-25]. Together, these data suggest that high polyphenol consumption could help prevent age-related cognitive decline.

\section{Polyphenol classification, chemical structure and food content}

Polyphenols are phytochemicals now considered essential micronutrients. Polyphenols can be divided into four main classes based on their structure (Fig. 1): flavonoids, phenolic acids, stilbenes and lignans [26]. Flavonoids possess a common structure consisting of two aromatic rings bound by three carbon atoms to form an oxygenated heterocycle $\left(\mathrm{C}_{6}-\mathrm{C}_{3}-\mathrm{C}_{6}\right)$. Based on the hydroxylation pattern of the oxygenated heterocycle and the arrangement of the hydroxyl groups, flavonoids can be divided into four subgroups: 1) flavonols, found in onions, broccoli and chocolate, 2) chalcones, 3) flavones, present in apples, and 4) anthocyanins, found in blueberries, strawberries, red wine and common beans [27, 28]. Flavones can be further divided into four subclasses: i) flavanones, present in citrus fruits and oregano, ii) flavanols, which are abundant in green tea, red wine and chocolate, iii) flavones, found in parsley, celery and olives, and iv) isoflavones, which are mainly found in soy $[27,28]$. Flavanols may be polymerized to generate flavanoids, also known as tannins or proanthocyanidins (PAs). Phenolic acids can be further classified into derivatives of benzoic acid $\left(\mathrm{C}_{6}-\mathrm{C}_{1}, 2\right)$, found in blackberries, red wine or black tea and massively in nuts such as chestnut, and derivatives of cinnamic acid $\left(\mathrm{C}_{6}-\mathrm{C}_{3}\right)$, found in red wine, plums and olives $[27,28]$. Stilbenes, found in lingonberries and cranberries [27,28], are in turn composed of two aromatic rings bound by a methylene bridge and can be found in cis and trans forms, which have different chemical and biological properties. Interconversions between trans and cis forms are observed with heat or UV radiation. Resveratrol can also occur in dimer or trimer forms as viniferins, found in red wine. Polyphenols also include lignans, which are precursors of parietal plant polymers that constitute factors of defense against pathogens and are characterized by a 1,4diarylbutane structure. They are found in olive oil and sesame seeds and oil [27, 28].

As mentioned above, in this review we will focus on polyphenols from berries for their interest in the prevention of age-related cognitive decline and also of the most prevalent age-related neurodegenerative diseases. Specifically, we will review and synthesize current knowledge regarding flavanols such as catechins and epicatechins and their oligomers, the PAs, which are found in grapes, as well as anthocyanins, mainly studied in relation to blueberries. Finally, we will focus on a particular stilbene, resveratrol, known to be present in grapes and at the center of considerable interest in the scientific community in recent years.

\section{Cognitive impairment}

\subsection{Aging brain}

Cognitive aging is characterized by an age-related decrease in elementary and advanced mental abilities such as concentration, working and long-term memory, reasoning, judgment, problem solving and speed of information processing [29]. This affects different abilities in individuals and can lead to decreased self-esteem and quality of life and take a "natural" or pathological form. Age-related cognitive decline is 


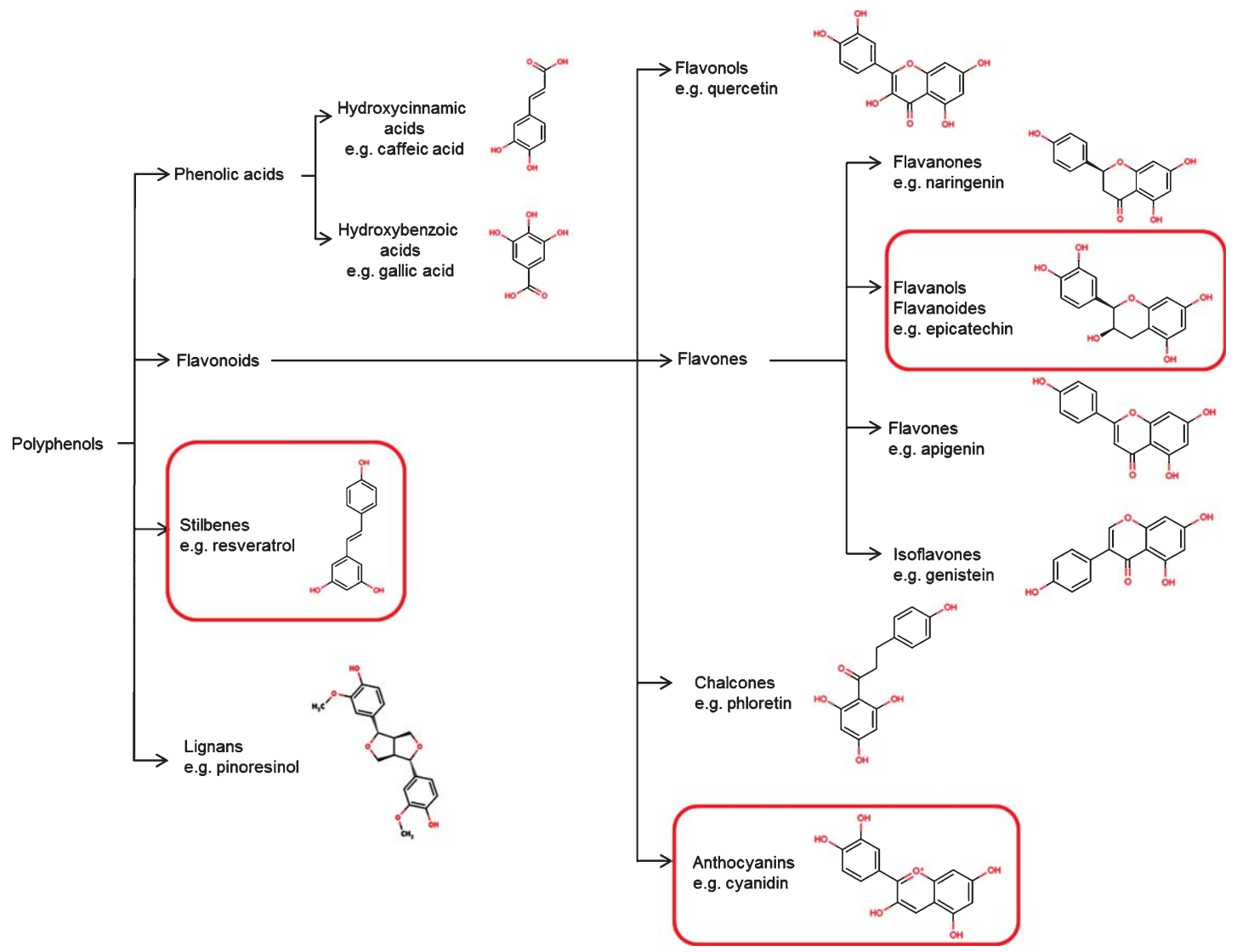

Fig. 1. Classification and chemical structure of the main classes of polyphenols (modified from Spencer et al., 2008 [209]).

the term used to describe the non-pathological form of memory deterioration, and identifies the decline in cognitive function consequent to the aging process that is within normal limits, given a person's age. It is a complex process, with the first signs emerging in humans in midlife (between 35 and 65 years), even without specific neurodegenerative lesions. Some pathological forms of aging may occur in addition to this "normal" cognitive decline. Among them, AD, the most common cause of dementia, affecting more than 24 million individuals worldwide [30], is irreversible in our present state of knowledge, as the only available treatments are purely symptomatic [31].

The aged brain exhibits numerous structural and functional alterations, which could underlie the decline of cognitive and motor abilities. Furthermore, cerebral lesions characteristic of AD (amyloid plaques and neurofibrillary tangles) are frequently observed during "normal" brain aging, in individuals with no cognitive symptoms [32,33]. It is widely admitted that dementia is an unavoidable process beyond a certain stage of aging, and that a con- tinuum exists between "normal" cognitive decline during aging and dementia [34], which could thus be considered an "exaggeration" or "acceleration" of aging. Thus, pathological cognitive aging appears to overlap with non-specific processes related to the "normal" aging of the brain, which also lead to cognitive impairment, and the relationship between the two is still unclear. Even the relevance of differentiating between the two processes with respect to the expression of cognitive symptoms is controversial. It has been shown that multiple brain lesions that are found in dementia also appear with normal aging; although their density and distribution are usually lower in healthy subjects [35]. Before the development of irreversible dementia, progressive cognitive decline is noticeable by the occurrence of minor cognitive problems that affect 15 to $20 \%$ of the population aged 65 years or more, but which represent an unstable state [36]. The natural evolution of this mild cognitive impairment could still be influenced by the implementation of secondary preventive measures. 
In this context, modifying environmental factors such as food and nutrition offers great opportunities for primary preventive strategy during the asymptomatic phase. Hence, any nutritional strategy defined should aim to prevent or delay the evolution toward dementia, in order to promote the maintenance of a satisfactory cognitive state and to avoid the dependence of elderly citizens in our modern society.

\subsection{Neurodegenerative diseases}

\subsubsection{Alzheimer's disease}

Alzheimer's disease (AD) is the most prevalent neurodegenerative disorder in the world, exerting an escalating socioeconomic burden on modern society $[37,38]$. Most often, $\mathrm{AD}$ is diagnosed in people over 65 years of age [39], who develop a progressive pattern of cognitive and functional impairments [40, 41] that gradually increase as the disease advances. Memory impairment, in particular the loss of the ability to form and retain new episodic memories, is a hallmark of early $\mathrm{AD}$ and may help in differentiating $\mathrm{AD}$ from common age-related cognitive decline. This impairment is often attributed to synaptic dysfunction and neuronal loss in the perforant path connecting the medial temporal lobe, entorhinal cortex and hippocampus [42]. Accordingly, cognitive changes in $\mathrm{AD}$ start with specific difficulties in the encoding and storage of new information, also indicative of a deficiency in semantic memory [43-45] and executive function impairment [46]. The etiology of $\mathrm{AD}$ is not well understood, except in 1 to $5 \%$ of cases in which genetic differences can be identified [47]. It is increasingly recognized that $\mathrm{AD}$ is a proteinopathy characterized by specific neuropathological markers: amyloid deposits, tau-laden tangles and the loss of neurons and synapses in the cerebral cortex and subcortical regions, associated with gross atrophy of the affected regions [48-55]. The accumulation of amyloid beta $(\mathrm{A} \beta)$ fragments is thought to be due to the uncontrolled cleavage and defective clearance of amyloid precursor protein [49]. Current treatments only partly alleviate symptoms but cannot stop or reverse the progression of the disease. Due to their favorable safety profile and availability, dietary approaches, in particular using polyphenol-enriched diets [56-58], are drawing attention as tools to prevent AD development [59-64]. The use of cheap and widely available compounds, like polyphenols, as nutraceutical or pharmaceutical tools in brain disorders such as AD may provide new strategies for the prevention or delay of cognitive decline.

\subsubsection{Parkinson's disease}

Parkinson's disease (PD) is a degenerative disorder of the central nervous system with no known cause, and is more common in older people, with most cases occurring after the age of 50 [65]. Dopamineinnervated brain structures, namely in the basal ganglia, are the most seriously affected brain areas in PD [66]. The clinical expression of PD mostly affects motor capacity, but patients often presents neuropsychiatric symptoms including depression, apathy, anxiety, hallucinations and cognitive dysfunction, reaching a prevalence of about 30 to $40 \%$ at advanced stages of the disease [67, 68]. Previous observations suggest that the neuropsychological profiles of PD and AD are different, with PD subjects being better at recall but worse at praxis than those with AD [69]. PD patients also display impairments in verbal fluency, visual perception and performance tasks $[69,70]$, suggesting impairments in the executive and visuospatial domains [71]. Many risk and protective factors for PD have been investigated. An increased risk of PD is associated with exposure to certain pesticides, insecticides and heavy metals [72-74], in contrast with a lower risk in tobacco smokers [74], coffee consumers [75] and individuals treated with anti-inflammatory drugs [74]. Although modern treatments are effective at managing the early motor symptoms of the disease [76], and surgery and deep-brain stimulation can be of use when drugs do not suffice to control symptoms [77], as there is currently no cure for PD. Interestingly, a diet enriched in polyphenol compounds has shown some efficacy in alleviating the symptoms of PD [78]. For example, in MPTP-injected mice, a toxin known to induce neuronal death, resveratrol was able to prevent MPTP-induced depletion of striatal dopamine, and to maintain striatal tyrosine hydroxylase protein levels, two neuropathological markers observed in PD patients $[78,79]$.

\section{The effects of berries on age-related cognitive decline}

Most studies of berries and age-related cognitive decline focus on specific berries high in antioxidants such as blueberries, strawberries or grapes. Blueberries, which contain large amounts of polyphenols, exert a greater antioxidant capacity than most 
other fruits and vegetables [80]. A number of studies suggest that the consumption of blueberries delays age-related physiological and functional deficits. For example, the daily consumption of blueberry juice for 12 weeks improves episodic memory performance in older adults (mean age: 76.2 years) [13]. Consistent with these results, work carried out in aged rats has shown the beneficial effects of blueberries on memory and motor performance, resulting in the attenuation of memory decline as evaluated in object recognition and spatial working memory tasks [9, 81]. From a mechanistic point of view, a blueberryenriched diet administered to very old rats (24 months old) compared to younger rats normalizes the level of NMDA-receptor-dependent long-term potentiation (LTP) in their hippocampus. LTP is widely recognized as a cellular correlate of memory formation, and this result suggests the normalization of synaptic plasticity by diet [82]. A more recent study in a senescence-accelerated mouse model also suggests that the beneficial effects of blueberry on cognitive decline could be due to an increase in the expression of phosphorylated extracellular signal-regulated kinases (ERKs). The authors of this study proposed that this promnesic effect of blueberry polyphenols may be due to their antioxidant activity, their capacity to activate superoxide dismutase (SOD) and to reduce malondialdehyde content [83]. However, it is currently admitted that the effects of blueberry extracts on cognitive functions involve more than their antioxidant actions. Thus, a diet containing blueberry extracts significantly decreases brain levels of nuclear factor-kappa B (NF- $\mathrm{B}$ ) (involved in the control of immune and inflammatory responses) in aged rats compared to controls [81]. These brain levels of NF- $\kappa \mathrm{B}$ are significantly higher in aged rats than younger ones [84]. These results are in accordance with the known effect of flavonoids on cellular signaling, especially on NF-кB activity [85, 86]. Studies on strawberries highlight the high antioxidant and antiinflammatory activities of these fruits, which may prevent the appearance of neurochemical and behavioral alterations with aging. Animal studies show that a strawberry supplement prevents the effects of aging on neuronal signal transduction and improves memory processes in aged rats [84, 87] and in a rodent model of accelerating aging [88]. The grape is particularly rich in flavonoids including catechins, epicatechins and quercetins as well as anthocyanins and PAs, all known to have potent antioxidant capacities. The "French Paradox" has sparked a renewed interest in grape polyphenols with respect to their potential benefits to human health, including brain health. Indeed, the strikingly lower incidence of coronary disease in France compared with other western countries has opened up a field of questions, and the hypothesis of the protective role of the oxidation of polyphenols contained in red wines has emerged and has been widely studied since. De facto, the nutritional properties of grapes as the source of wine polyphenols are also the subject of numerous studies. Similar to results obtained with blueberry juice, Concord grape juice consumption for 12 weeks leads to an improvement of memory performance evaluated by the Californian learning test in older humans [14]. A similar effect has been observed in aged rats with Concord grape juice consumption [89]. Specific extracts of the berries (e.g. grape seed extracts, GSEs) are more commonly used for nutritional intervention because they are highly enriched in polyphenols, in particular in flavanols, anthocyanins and resveratrol. These extracts are suitable for nutritional supplementation, as they contain a higher concentration of polyphenols than fruits or juices, and this facilitates the identification of their functional and behavioral effects and the study of the underlying neurobiological mechanisms. More recently, the beneficial effects of blackberries and mulberries on age-related memory deficits as well as on motor behavior have been shown in aged rats [90] and in senescence-accelerated mice [91].

Together, these data argue in favor of the use of berry extracts as dietary supplements to target memory performance, and to better understand the mechanisms underlying their beneficial effects.

\section{Flavanols}

\subsection{Effects on age-related cognitive decline}

A recent study has provided detailed information on habitual dietary intake of flavanols, in particular flavan-3-ol monomers, PAs and theaflavins, in humans aged 18-64 years in the European Union. This study demonstrates that dietary intake amounts for flavan-3-ol monomers, PAs and theaflavins vary significantly across European countries $(181 \mathrm{mg} / \mathrm{d}$ to $793 \mathrm{mg} / \mathrm{d}$ ). Moreover, the average habitual intake of flavan-3-ols is considerably below the amounts used in most dietary intervention studies [92]. Several studies have shown the beneficial effects of flavanols on cognitive performance. Their molecular impact 
has also been investigated in vitro and in vivo. Some studies have evaluated the benefits of supplementation with flavanols from GSEs. Indeed, GSEs are a rich source of monomeric phenolic compounds such as catechin, epicatechin and dimeric, trimeric and tetrameric PAs. Supplementation with GSE significantly improved the memory performance of aged rats evaluated using a brightness-discrimination task in a T-maze. This beneficial effect might be explained by reduced blood glucose levels and decreased oxidative stress in the hippocampus [93, 94]. Indeed, the promnesic effects of GSEs are due to the stimulation of antioxidant defense mechanisms, attenuating lipid peroxidation and protein oxidation. A positive effect on the cholinergic system, which also underlies the beneficial activity of GSEs on memory, has also been observed in adult and middle-aged rats [93, 95]. A recent study has also evaluated the impact of pure flavanols on memory and the underlying molecular mechanisms in 18-month-old male rats. A significant improvement in spatial working memory was observed in rats receiving pure flavanols (catechin and epicatechin) at levels similar to that found in blueberries $(2 \% \mathrm{w} / \mathrm{w})$ for 6 weeks. Interestingly, this behavioral effect was linked with an increase in hippocampal brain-derived neurotrophic factor (BDNF), thus confirming the therapeutic value of polyphenol extracts in memory processes [96]. Epicatechin, administered for 6 weeks, combined with physical exercise, enhances spatial learning and reference memory, increases angiogenesis and neuronal spine density in the hippocampal dentate gyrus (DG) of mice, and upregulates hippocampal genes associated with learning concomitant with the decreased expression of inflammation and cell death genes. In the absence of physical exercise, epicatechin still has an effect, but to a lower extent, on spatial memory retention and angiogenesis in the DG as well as on gene expression [97]. The flavanols (-)-epicatechin and 3-O-methyl-(-)-epicatechin, one of its metabolites, exerted a stimulatory effect on ERK1/2 and on the downstream transcription factor C-AMP Response Element-Binding protein (CREB). Moreover, these flavanols protected neurons against oxidative damage via a mechanism involving the suppression of c-Jun $\mathrm{N}$-terminal kinase (JNK), and its downstream partners, c-Jun and pro-caspase-3 $[98,99]$. In addition, it has been shown in vitro, in glial cells, that catechin from green tea protects cells from oxidative stressinduced DNA damage and decreases cell death by reducing NF- $\mathrm{BB}$ and p53 activity [100]. Moreover, physiologically relevant concentrations of epicate- chin and catechin inhibit TNF- $\alpha$, which is released by primary glial cells, suggesting that flavanols may also have the potential to exert anti-inflammatory effects in the central nervous system [101].

\subsection{Therapeutic potential in neurodegenerative diseases}

Data gathered in various models of neurodegenerative diseases provide arguments for the use of flavanols in neuroprotection. For example, various flavanol-rich cocoa extracts inhibit the oligomerization of $A \beta$ fragments 40 and 42 in the mouse hippocampal region, while one extract, Lavado, also rescues the LTP response after damage by $\mathrm{A} \beta$ fragments [102]. Along these lines, oral administration of flavanol epicatechin prevents defects in spatial learning and memory performance observed after the injection of $A \beta$ fragments $25-35$ directly into the CA1 subregion of the hippocampus of rats [103]. Epicatechins also inhibit damage due to reactive oxygen species (ROS) generated by $A \beta$ fragments [103]. Similarly, Wistar rats fed catechins for 21 days prior to intracerebroventricular injections of streptozotocin (STZ), used to model sporadic AD, present a dose-dependent amelioration of both path length and latency in the Morris Water Maze task [104]. More interestingly, Desideri et al. have tested the effect of cocoa flavanols on humans suffering from mild cognitive impairment and found that, on average, greater daily oral doses of flavanols over a period of 8 weeks are associated with an enhancement of cognitive function [105]. These studies support the potential of flavanols in preventing memory loss, cognitive impairment and oxidative stress induced by $\mathrm{A} \beta$ fragments, all prominent features of AD.

Moreover, several studies have provided evidence of the neuroprotective activity of flavanols in both cellular and animal models of PD. For example, the intragastric administration of catechins in mice protects, in a dose-dependent manner, substantia nigra dopaminergic neurons from the neurodegenerative effects of 1-methyl-4-phenyl1,2,3,6-tetrahydropyridine (MPTP) injections [106]. In a similar experiment, SH-SY5Y cells exposed to the 1-methyl-4-phenylpyridinium ion $\left(\mathrm{MPP}^{+}\right)$ showed greater viability, as well as decreased ROS production when pretreated with catechins [107]. However, the neuroprotective activity of catechins may result not only from their free-radical scavenger properties but also from their implication in several 
cellular signaling pathways involving JNK or GSK$3 \beta$ [106]. Furthermore, in the 6-hydroxydopamine (6-OHDA) rat model of PD, intraperitoneal treatment with catechins prevents working memory deficits and mesencephalic dopamine loss as well as motor impairments [108]. Taken together, these findings suggest that flavanols may have therapeutic potential in neurodegenerative diseases, particularly in the PD field. Further investigations are required to elucidate the molecular mechanisms underlying the neuroprotective effects of flavanols.

\section{Anthocyanins}

\subsection{Effects on age-related cognitive decline}

Most studies performed in order to assess the potential effects of anthocyanins on health have been carried out using fruit extracts rich in anthocyanins, but some have used metabolites of anthocyanins. Anthocyanins are major dietary components especially in those who routinely eat berries or derivatives such as juices or red wine [28]. Unlike other flavonoids which are absorbed and excreted, anthocyanins do not appear to undergo extensive metabolism to glucuronide and sulfate derivatives, and their excretion is low. In interventional studies in humans, the typical recovery of anthocyanins in the urine is $<0.1 \%$ of intake [109]. For instance, $\mathrm{Wu}$ et al. [110] have reported the total urinary excretion of anthocyanins from blueberries consumed by elderly women to be $0.004 \%$ of intake. These low recovery levels could be a consequence of anthocyanins undergoing structural rearrangements in response to $\mathrm{pH}$ changes. Such rearrangements are likely to occur in vivo as anthocyanins pass from a low $\mathrm{pH}$ in the stomach to the more basic conditions of the small intestine.

In rodent studies, the consumption of foods rich in anthocyanins prevents memory deficits [89, 111-113]. Thus, a 3-month supplementation with a blueberry-enriched diet improves spatial working memory performance of aged rats [9]. The activation of CREB and ERK1/2, an increase in the levels of both BDNF and pro-BDNF as well as of CaMKII, CaMKIV, PKA, Akt, mTOR and Arc/Arg3 in the hippocampus seems to underlie these behavioral effects. Similar effects have been shown using both pure anthocyanins and extracts. Thus, a 6-week supplementation with pure anthocyanins in 18-month-old rats induces significant improvements in spatial memory linked with an increase in hippocampal BDNF levels [96]. A purple sweet potato color extract administered for 4 weeks by gavage in a mouse model of accelerated aging induced by D-galactose (Dgal), attenuates D-gal-induced cognitive impairment, partly via the improvement of antioxidant and antiinflammatory responses [114]. In the same manner, in SAMP8 mice, a model of accelerated aging, 12 weeks of supplementation with a mulberry extract rich in anthocyanins improves learning and memory abilities and displays hepatoprotective effects through the regulation of mitogen-activated protein kinases (MAPKs, e.g. JNK, p38, ERK) and the activation of Nrf2 [91]. Likewise, it has recently been shown that 8 weeks of supplementation with cyanidin-3O-galactoside from blueberries improves learning and memory in the same animal model. The recovery of cognitive and behavioral functions in aged animals could be explained by an improvement of oxidative status via the activation of SOD and a reduction in the malondialdehyde content of brain tissue and plasma. Furthermore, an increase in phosphorylated ERK in the hippocampus, an inhibition of damage to the pyramidal cell layer and more generally, an improvement of hippocampal neuron survival, have all been observed [83]. Interestingly, these beneficial effects of anthocyanins on cognitive function have also been reported in young mice (34 months old) and rats (10 weeks and 12 months old), in which they improve learning and memory performances. At the molecular level, these studies have reported reduced oxidative DNA damage in brain tissue, a lower level of lipid peroxidation, higher brain levels of ascorbic acid and glutathione, and a decrease in acetylcholinesterase activity, following treatment with anthocyanins. Moreover, the modulation of ERK1/2 activation and the increase of CREB, BDNF and pro-BDNF levels in the hippocampus have also been reported $[111,113,115$, 116]. More recently, an important effect on hippocampal synaptic plasticity has been evidenced in young rats (8 weeks old) fed for a short period (3 weeks) with blueberries by gavage. In addition to improved spatial memory acquisition and consolidation, increased levels of the polysialylated form of the neural cell adhesion molecule (PSANCAM), a marker of neuronal plasticity, in the DG, accompanied by an increase in hippocampal NR2Bcontaining NMDA receptors, have been observed in rats fed by gavage with blueberries [117]. It has also been suggested that polyphenols could act on the 
inflammatory process. The exposure of microglial cells to an anthocyanin-rich blueberry extract induces the significant suppression of the expression of both the iNOS and COX-2 genes, known to be involved in the inflammatory process [118]. However, in another study, when activated microglia were exposed to the pure anthocyanins, cyanidin and pelargonidin, no effects on iNOS expression or TNF- $\alpha$ release were observed [101].

\subsection{Therapeutic potential in neurodegenerative diseases}

Besides their abovementioned properties in aging, anthocyanins may alter specific pathophysiological processes related to various neurodegenerative disorders. For instance, Tarozzi et al. have shown that the anthocyanin cyanidin-3-O-glucoside (C3G) protects SH-S5Y 5 human cells against the neurotoxicity induced by $A \beta$ oligomers, probably by preventing them from binding to the cell membrane [119]. In addition, a recent in silico simulation has revealed that anthocyanins could induce conformational changes that activate FKPB52 [120], a protein complex known to inhibit the aggregation of tau [121]. In animal models, anthocyanin gavage for one week prior to an intracerebral injection of STZ prevents memory deficits in Wistar rats [122]. In a similar study, intraperitoneal treatment with anthocyanins also protected against the memory impairment elicited by injections of scopolamine, used to elicit memory impairment [123]. These studies support the potential of anthocyanins or their metabolites to prevent $\mathrm{AD}$ or slow its progression.

There is also evidence of the neuroprotective activity of anthocyanins in models of PD. For example, in primary cultures of midbrain cells, a series of anthocyanins isolated from blackcurrants, including delphinidin-3-O-glucoside and $\mathrm{C} 3 \mathrm{G}$, reduces dopaminergic cell death induced by rotenone [124], an insecticide known to cause nigral neurodegeneration in vivo. Anthocyanins display inhibitory effects on monoamine oxidase B (MAOB), an action similar albeit smaller than that of drugs currently used to treat early PD [125]. Together, these investigations highlight the therapeutic potential of anthocyanins in neurodegenerative diseases. However, more preclinical and clinical studies investigating the effects of pure anthocyanins and their derivatives are required to determine their potential benefits in $\mathrm{AD}$ or PD.

\section{Stilbenes: Resveratrol}

\subsection{Effects on age-related cognitive decline}

Resveratrol is a polyphenol found mainly in grapes and red wine. It possesses diverse biological activities that confer protection against oxidative stress, inflammation, cardiovascular disease, and cancer [126-130]. As mentioned previously, resveratrol also exerts beneficial effects on age-related cognitive impairment. Indeed, resveratrol can, for example, improve working memory, spatial learning and memory and spontaneous locomotor activity in various animal models such as healthy non-human primates (Microcebus murinus) or aged mice with LPS-induced deficits [25, 131, 132]. Recently, a significant enhancement of angiogenesis and neurogenesis has been observed in the DG of these mice [25]. One of the main hypotheses to explain how resveratrol induces these beneficial health effects in vivo is the modulation of sirtuin 1 (SIRT1), one of seven proteins belonging to the sirtuin family and an energy sensor involved in longevity. Many studies have evaluated this mechanism, seeking to determine if the interaction between SIRT1 and resveratrol is direct or indirect, a question still under debate. On the one hand, there are much data to support the hypothesis that SIRT1 is directly activated by resveratrol [126, 133-144]. On the other hand, resveratrol also indirectly inhibits the $\mathrm{PI} 3 \mathrm{~K} / \mathrm{mTOR} / \mathrm{S} 6 \mathrm{~K}$ pathway [145-149]. SIRT1 and mTOR could be members of the same sirtuin/mTOR network [150], and it is likely that mTOR (pro-aging pathway) and sirtuins (anti-aging pathway) antagonize each other [151]. Han et al. have investigated the possible existence of specific polyphenol-binding sites at the cell membrane level in the rat brain [152]. Their results suggest that the neuroprotective action of various polyphenols and resveratrol analogs could be mediated by the activation of common "receptor" binding sites that are particularly enriched at the level of the cell membrane.

In addition to the above pathways, resveratrol could act through the cyclooxygenase (COX) and 5-lipoxygenase cascades, thereby modulating the production of pro-inflammatory molecules [153]. Inhibitors of these enzymes are commonly used as anti-inflammatory drugs. Because resveratrol is an effective in vivo inhibitor of COX activity [154-156], its anti-inflammatory properties have been investigated. Intravenously administered resveratrol decreases neuroinflammation induced by 
ischemia/reperfusion [157]. The anti-inflammatory effects of resveratrol in aged mice could also be linked to its ability to inhibit factors involved in gene transcription such as MAPKs, AP-1 and NF- $\mathrm{KB}$ [133, 158-161]. The link between SIRT1 and NF-кB signaling is particularly interesting because, according to a number of authors, SIRT1 can prolong the lifespan by inhibiting NF- $\mathrm{BB}$ signaling to an extent sufficient to reverse gene expression changes associated with aging in mice $[160,162,163]$. Moreover, a reduction in the levels of inflammatory markers such as interleukin- $1 \beta$ has been observed in resveratrol-supplemented mice in both the plasma and hippocampus. The in vitro analysis of its impact on microglial cells has confirmed that resveratrol potently inhibits LPS-induced interleukin- $1 \beta$ production [131]. Thus, resveratrol could present an attractive alternative to current treatments against chronic inflammation. Resveratrol also has considerable antioxidant activity, although it is unclear if this is the result of a direct scavenging effect or the activation of pathways that upregulate natural cellular antioxidant defenses. Resveratrol can inhibit the production of ROS by neutrophils, monocytes, and macrophages [164-168]. In spontaneously hypertensive rats, which are prone to stroke, resveratrol significantly reduces markers of oxidative stress in the serum and urine [169]. Furthermore, in guinea pigs, resveratrol decreases the concentration of ROS generated by menadione [170]. These data indicate that resveratrol can suppress pathological increases in the peroxidation of lipids and other macromolecules in vivo, but whether the mechanism is direct, indirect or both has yet to be determined. There are other data in support of these protective effects. For instance, resveratrol can dramatically increase mitochondrial manganese SOD expression and activity in MRC-5 cells, as well as in mouse brain tissue [171]. Despite all these arguments, it is important to emphasize that, even if the scientific literature widely credit resveratrol with being responsible for the protective effects of red wine $[172,173]$, it is certainly not the only cause. Indeed, stilbene concentrations in red wine are so low that a human being would have to consume more than 60 liters daily to reach the levels required to increase longevity and provide the same protective effects as those observed in animal models [174]. Resveratrol is thus a minor component of the human diet, and its potential therapeutic use would only be probably possible at pharmacological doses.

A naturally dimethylated analog of resveratrol, pterosilbene, exhibits similar biological activities including an antioxidant activity [175]. However, pterostilbene has been shown to display a higher in vivo bioavailability, possibly due to increased lipophilicity induced by the substitution of a methoxy rather than a hydroxyl group [176]. Pterostilbene is a molecule found in blueberries [177] and grapes [178]. Unfortunately, there are no reported estimates regarding pterostilbene intake in humans. Joseph et al. [179] have reported that dietary pterostilbene is effective in reversing cognitive deficits in aged rats with a correlation with hippocampal pterostilbene levels. Quite recently, it has been shown that, at equivalent and diet-achievable doses, pterostilbene is a more potent modulator of cognition and cellular stress than resveratrol, likely driven by increased peroxisome proliferator-activated receptor alpha (PPAR- $\alpha$ ) expression and the aforementioned methoxy moiety [180].

\subsection{Therapeutic potential in neurodegenerative diseases}

The evidence of a neuroprotective action of resveratrol in vitro and in vivo has generated a lot of interest pertaining to its use in preventing neurodegenerative diseases [181]. For example, in transgenic animal models of AD-like neuropathology, chronic resveratrol administration promotes neuronal survival in the hippocampus [182], prevents learning deficits [182] and reduces $A \beta$ plaque pathology by 50 to $90 \%$ depending on the brain region studied [183]. The potential therapeutic activity of resveratrol in AD has also been reported by Marambaud et al. who tested the neuroprotective activity of various polyphenols such as resveratrol, quercetin and catechin in series of cell lines. Resveratrol was particularly effective in reducing, in a dose-dependent manner, the production of intracellular $A \beta$ peptides via a proteasome-dependent mechanism [184]. In animals, oral administration of a grape-seed polyphenol extract containing resveratrol significantly attenuates the development of tau neuropathology in a mouse model of AD [185]. Treatment with a standardized grape polyphenol preparation containing resveratrol leads to the improvement of cognitive function and greatly reduces total amyloid content in the brain of J20 AD mice, an animal model of $\mathrm{A} \beta$ pathology [186]. According to a recent report, chronic resveratrol administration leads to decreases in the ratio of soluble $\mathrm{A} \beta 42 / \mathrm{A} \beta 40(-42 \%)$ and in the concentration of insoluble human tau $(-93 \%)$ in the parietotemporal cortex of 18-month-old mice in a triple-transgenic 
model of AD [187]. More importantly, because this study used an end wash-out study design, it showed that these effects of resveratrol on the $A \beta 42 / A \beta 40$ ratio and insoluble tau lasted for at least 3 months after the end of treatment, consistent with the diseasemodifying effects of resveratrol.

In the PD field, a dose-dependent protective role of resveratrol on dopaminergic neurons in midbrain slice cultures from Wistar rats exposed to cytotoxic drugs, $\mathrm{MPP}^{+}$or thrombin has been reported, highlighting the possible antioxidant effect of resveratrol [188]. Studies carried out in mice show that resveratrol administration protects mice from MPTP-induced hydroxyl radical overloading and dopaminergic neuron loss [79, 189]. This action has been attributed to the resveratrol-induced activation of SIRT1, as the protective effect is lost in the presence of a SIRT1 inhibitor [190]. Overall, although the modulating effect on oxidative stress remains an essential element in the neuroprotective effect of resveratrol, it is becoming clear that other cellular mechanisms also underlie such effects of polyphenols and their metabolites in $\mathrm{AD}$ and $\mathrm{PD}$ [191]. The consumption of resveratrol-rich foods, such as berries, cocoa and grapes [64], throughout life holds strong potential to limit or delay neurodegeneration and to prevent or reverse the age-dependent deterioration in cognitive performance.

\section{Brain bioavailability}

In order to understand whether polyphenols and their metabolic derivatives are capable of directly inducing neuroprotective effects, it is important to know whether they can access the central nervous system. To enter the brain, absorbed polyphenols or their active metabolites must first cross the blood brain barrier (BBB). Some studies have reported that polyphenols can be found in brain tissue after oral ingestion. For instance, some flavanols, such as metabolites of catechin and epicatechin, can be found in the rat brain following oral intake [9, 97, 192-194]. Some flavonoids, including dietary anthocyanins such as cyanidin-3-rutinoside and pelargonidin-3-glucoside, are also able to cross the BBB in relevant in vitro and in situ models [195]. Moreover, anthocyanins have also been detected in different regions of the brain of rats [196] and pigs fed blueberries [197, 198], and at trace levels in brains of rats fed a blueberry extractenriched diet containing anthocyanins for 10 weeks [10]. Similarly, in pigs given a 4-week supplemen- tation of blueberry extract containing anthocyanins (undefined amounts), $300 \mathrm{pg} / \mathrm{g}$ of anthocyanins have been detected in the cerebellar tissue and $700 \mathrm{pg} / \mathrm{g}$ in the eye tissue [197]. In a much shorter time frame, $18 \mathrm{~h}$ after the administration of pelargonidin by gavage $(50 \mathrm{mg} / \mathrm{kg}$ of body weight), unmetabolized anthocyanin has been detected in the rat brain at a concentration of $0.2 \mathrm{nmol} / \mathrm{g}$ (wet weight) [199]. In contrast, in another study, there were no detectable anthocyanins in the brain of rats $24 \mathrm{~h}$ after acute administration by gavage of $2.8 \mathrm{ml}$ of raspberry juice, which is a nutritionally-relevant dose equivalent to $700 \mathrm{ml}$ of juice for a $70 \mathrm{~kg}$ human [200]. However, several reports have confirmed that orally administered resveratrol after being absorbed by the organism, crosses the BBB and is incorporated into the brain [201-204]. Despite the brain functional effect of polyphenols evidenced in human, there is a lack of information concerning their brain bioavailability.

How polyphenols cross the BBB is still under debate. To gain access to the brain, a polyphenol must be highly lipid-soluble, or subject to transport processes [195, 205]. In addition, polyphenols are regarded as xenobiotics by the body, and their bioavailability can be severely affected by ABC transporter efflux pumps which are present at the BBB. These pumps reject xenobiotics across the BBB, from the brain to the blood $[195,205,206]$. However, certain polyphenols are known to inhibit these transporters, thereby facilitating the accumulation of other substrates into the brain, increasing their central bioavailabilty [207, 208]. In addition, most studies have been performed in animals with metabolic rates and levels of transporter expression, which differs from humans. Thus, the conclusion of these studies must be interpreted carefully pertaining to BBB transport and biodistribution occurring in a human setting.

Finally, whether the concentrations of polyphenols or their metabolites found in cerebral tissue are sufficient to exert pharmacological actions remain to be determined. However, the accumulating data at least suggest that the brain is not completely impermeable to these families of compounds.

\section{Conclusion}

The constantly increasing number of elderly people is dramatically linked with an increase in the prevalence of neurodegenerative diseases. This is one of the major medical and socio-economic challenges of modern societies. Various mechanisms 
leading to memory deficiency with aging have been described. Among these, inflammation, the modification of oxidative status and DNA damage can all have a strong impact on memory processes, reducing cerebral plasticity and leading to the loss of neurons and the diminution of synaptic connectivity. The development of functional foods with "anti-aging" activity is thus of overwhelming interest to both the general public and scientific communities. As discussed in this review, it appears that berries, which are rich in phenolic compounds, exert beneficial effects by attenuating age-related cognitive decline and, possibly as well, on the development of neurodegenerative diseases. Both berries and well-characterized polyphenols such as flavanols, anthocyanins and resveratrol can have beneficial effects on the brain, and more broadly, have been shown to display important biological properties. To better understand their neuroprotective effects, it is essential to identify their active ingredients and their mechanisms of action. Polyphenols are ubiquitous in plant foods and beverages and can therefore be consumed daily in the diet. They have often been generically referred to as "antioxidants", but a number of different mechanisms underlie the potential of polyphenols to improve neurological health, including their ability to interact with neuronal and glial signaling, to reduce neuronal damage and loss induced by neurotoxins or neuroinflammation, to alter ROS production as well as to attenuate the accumulation of neuropathological markers, such as $A \beta$. However, the majority of the data used to support this neuroprotective effect comes from studies dealing with a complex mix of compounds with high polyphenol contents. Furthermore, the effects of the structural changes undergone by polyphenols during metabolism and their interaction with the BBB have not yet been adequately studied to draw clear conclusions on their cerebral bioavailability. Moreover, most of these studies have been performed in animals, and it is now important to develop clinical studies to validate the data gathered so far. Indeed, nutritional intervention studies must be carried out to confirm that polyphenols could be a valuable asset in strategies aimed at delaying or preventing age-related cognitive decline and the development of neurodegenerative diseases in human. Since there are much evidences in the literature in favor of the preventive and therapeutic benefits of polyphenols, to understand their mechanisms, the timing and scope of administration of these compounds in aging and disease processes is an achievable goal. Further investigations are now needed to expand our understanding of the dynamic role these dietary compounds play in the alleviation of age-associated risk factors in the brain.

\section{Acknowledgments}

We thank the Aquitaine regional council for its financial support.

\section{References}

[1] Joseph JA, Shukitt-Hale B, Casadesus G. Reversing the deleterious effects of aging on neuronal communication and behavior: Beneficial properties of fruit polyphenolic compounds. The American Journal of Clinical Nutrition. 2005;81(1 Suppl):313S-6S.

[2] Esposito E, Rotilio D, Di Matteo V, Di Giulio C, Cacchio $\mathrm{M}$, Algeri S. A review of specific dietary antioxidants and the effects on biochemical mechanisms related to neurodegenerative processes. Neurobiology of Aging. 2002;23(5): 719-35.

[3] Evans DA, Funkenstein HH, Albert MS, Scherr PA, Cook NR, Chown MJ, et al. Prevalence of Alzheimer's disease in a community population of older persons. Higher than previously reported. JAMA. 1989;262(18):2551-6.

[4] Nicita-Mauro V. Parkinson's disease, Parkinsonism and aging. Archives of Gerontology and Geriatrics Supplement. 2002;8:225-38.

[5] Queen BL, Tollefsbol TO. Polyphenols and aging. Current Aging Science. 2010;3(1):34-42.

[6] Gomez-Pinilla F. Brain foods: The effects of nutrients on brain function. Nature Reviews Neuroscience. 2008;9(7):568-78.

[7] Haque AM, Hashimoto M, Katakura M, Tanabe Y, Hara Y, Shido O. Long-term administration of green tea catechins improves spatial cognition learning ability in rats. The Journal of Nutrition. 2006;136(4):1043-7.

[8] Kaur T, Pathak CM, Pandhi P, Khanduja KL. Effects of green tea extract on learning, memory, behavior and acetylcholinesterase activity in young and old male rats. Brain and Cognition. 2008;67(1):25-30.

[9] Williams CM, El Mohsen MA, Vauzour D, Rendeiro C, Butler LT, Ellis JA, et al. Blueberry-induced changes in spatial working memory correlate with changes in hippocampal CREB phosphorylation and brain-derived neurotrophic factor (BDNF) levels. Free Radical Biology \& Medicine. 2008;45(3):295-305.

[10] Andres-Lacueva C, Shukitt-Hale B, Galli RL, Jauregui O, Lamuela-Raventos RM, Joseph JA. Anthocyanins in aged blueberry-fed rats are found centrally and may enhance memory. Nutritional Neuroscience. 2005;8(2):111-20.

[11] Shukitt-Hale B, Lau FC, Joseph JA. Berry fruit supplementation and the aging brain. Journal of Agricultural and Food Chemistry. 2008;56(3):636-41.

[12] Dinges DF. Cocoa flavanols, cerebral blood flow, cognition, and health: Going forward. Journal of Cardiovascular Pharmacology. 2006;47 Suppl 2:S221-3. 
[13] Krikorian R, Shidler MD, Nash TA, Kalt W, VinqvistTymchuk MR, Shukitt-Hale B, et al. Blueberry supplementation improves memory in older adults. Journal of Agricultural and Food Chemistry. 2010;58(7):3996-4000.

[14] Krikorian R, Nash TA, Shidler MD, Shukitt-Hale B, Joseph JA. Concord grape juice supplementation improves memory function in older adults with mild cognitive impairment. The British Journal of Nutrition. 2010;103(5):730-4.

[15] Krikorian R, Boespflug EL, Fleck DE, Stein AL, Wightman $\mathrm{JD}$, Shidler MD, et al. Concord grape juice supplementation and neurocognitive function in human aging. Journal of Agricultural and Food Chemistry. 2012;60(23): 5736-42.

[16] Letenneur L. Risk of dementia and alcohol and wine consumption: A review of recent results. Biological Research. 2004;37(2):189-93.

[17] Letenneur L, Proust-Lima C, Le Gouge A, Dartigues JF, Barberger-Gateau P. Flavonoid intake and cognitive decline over a 10-year period. American Journal of Epidemiology. 2007;165(12):1364-71.

[18] Spencer JP, Vauzour D, Rendeiro C. Flavonoids and cognition: The molecular mechanisms underlying their behavioural effects. Archives of Biochemistry and Biophysics. 2009;492(1-2):1-9.

[19] Sun AY, Simonyi A, Sun GY. The "French Paradox" and beyond: Neuroprotective effects of polyphenols. Free Radical Biology \& Medicine. 2002;32(4):314-8.

[20] Barger JL, Kayo T, Vann JM, Arias EB, Wang J, Hacker $\mathrm{TA}$, et al. A low dose of dietary resveratrol partially mimics caloric restriction and retards aging parameters in mice. PloS One. 2008;3(6):e2264.

[21] Agarwal B, Baur JA. Resveratrol and life extension. Annals of the New York Academy of Sciences. 2011;1215:138-43.

[22] Pearson KJ, Baur JA, Lewis KN, Peshkin L, Price NL, Labinskyy N, et al. Resveratrol delays age-related deterioration and mimics transcriptional aspects of dietary restriction without extending life span. Cell Metabolism. 2008;8(2):157-68.

[23] Valenzano DR, Terzibasi E, Genade T, Cattaneo A, Domenici L, Cellerino A. Resveratrol prolongs lifespan and retards the onset of age-related markers in a short-lived vertebrate. Current Biology : CB. 2006;16(3):296-300.

[24] Dal-Pan A, Terrien J, Pifferi F, Botalla R, Hardy I, Marchal $\mathrm{J}$, et al. Caloric restriction or resveratrol supplementation and ageing in a non-human primate: First-year outcome of the RESTRIKAL study in Microcebus murinus. Age (Dordr). 2011;33(1):15-31.

[25] Harada N, Zhao J, Kurihara H, Nakagata N, Okajima $\mathrm{K}$. Resveratrol improves cognitive function in mice by increasing production of insulin-like growth factor-I in the hippocampus. The Journal of Nutritional Biochemistry. 2011;22(12):1150-9.

[26] Manach C, Scalbert A, Morand C, Remesy C, Jimenez L. Polyphenols: Food sources and bioavailability. The American Journal of Clinical Nutrition. 2004;79(5):727-47.

[27] Collin S, Crouzet J. Polyphénols et procédés: Transformation des polyphénols au travers des procédés appliqués à l'agroalimentaire: Lavoisier; 2011.

[28] Phenol-Explorer. http://www.phenol-explorer.eu

[29] Park DC, Reuter-Lorenz P. The adaptive brain: Aging and neurocognitive scaffolding. Annual Review of Psychology. 2009;60:173-96.
[30] Blennow K, de Leon MJ, Zetterberg H. Alzheimer's disease. Lancet. 2006;368(9533):387-403.

[31] Walker LC, Ibegbu CC, Todd CW, Robinson HL, Jucker M, LeVine H, 3rd, et al. Emerging prospects for the diseasemodifying treatment of Alzheimer's disease. Biochemical Pharmacology. 2005;69(7):1001-8.

[32] Seno H, Parisi JE, Okazaki H, Ishino H. 478 Neuronal Loss, Neurofibrillary Tangles and Senile Plaques in normal aging and Alzheimer's disease: A quantitative study of the hippocampus and the entorhinal cortex. Neurobiology of Aging. 1996;17(4):S119.

[33] Morris JC, Storandt M, McKeel DW, Jr., Rubin EH, Price JL, Grant EA, et al. Cerebral amyloid deposition and diffuse plaques in "normal" aging: Evidence for presymptomatic and very mild Alzheimer's disease. Neurology. 1996;46(3):707-19.

[34] Drachman DA. If we live long enough, will we all be demented? Neurology. 1994;44(9):1563-5.

[35] Dickson DW, Crystal HA, Mattiace LA, Masur DM, Blau $\mathrm{AD}$, Davies $\mathrm{P}$, et al. Identification of normal and pathological aging in prospectively studied nondemented elderly humans. Neurobiology of Aging. 1992;13(1):179-89.

[36] Petersen RC. Mild cognitive impairment as a diagnostic entity. Journal of Internal Medicine. 2004;256(3):183-94.

[37] Wimo A, Jönsson L, Bond J, Prince M, Winblad B. The worldwide economic impact of dementia 2010. Alzheimers Dement. 2013;9(1):1-11.e3.

[38] Meek PD, McKeithan K, Schumock GT. Economic considerations in Alzheimer's disease. Pharmacotherapy. 1998;18(2 Pt 2):68-73; discussion 9-82.

[39] Brookmeyer R, Gray S, Kawas C. Projections of Alzheimer's disease in the United States and the public health impact of delaying disease onset. American Journal of Public Health. 1998;88(9):1337-42.

[40] Forstl H, Kurz A. Clinical features of Alzheimer's disease. European Archives of Psychiatry and Clinical Neuroscience. 1999;249(6):288-90.

[41] Khan Z, Martín-Montañez E, Navarro-Lobato I, Muly E. Memory deficits in aging and neurological diseases. Prog Mol Biol Transl Sci. 2014;122:1-29.

[42] Celone KA, Calhoun VD, Dickerson BC, Atri A, Chua EF, Miller SL, et al. Alterations in Memory Networks in Mild Cognitive Impairment and Alzheimer's Disease: An Independent Component Analysis. The Journal of Neuroscience. 2006;26(40):10222-31.

[43] Gainotti G, Quaranta D, Vita MG, Marra C. Neuropsychological Predictors of Conversion from Mild Cognitive Impairment to Alzheimer's Disease. Journal of Alzheimer's Disease. 2014;38(3):481-95.

[44] Jak AJ, Bangen KJ, Wierenga CE, Delano-Wood L, CoreyBloom J, Bondi MW. Contributions of Neuropsychology and Neuroimaging to Understanding Clinical Subtypes of Mild Cognitive Impairment. In: Alireza M, editor. International Review of Neurobiology. Volume 84: Academic Press; 2009. pp. 81-103.

[45] Peña-Casanova J, Sánchez-Benavides G, de Sola S, Manero-Borrás RM, Casals-Coll M. Neuropsychology of Alzheimer's Disease. Archives of Medical Research. 2012;43(8):686-93.

[46] Molinuevo JL, Gómez-Anson B, Monte GC, Bosch B, Sánchez-Valle R, Rami L. Neuropsychological profile of prodromal Alzheimer's disease (Prd-AD) and their 
radiological correlates. Archives of Gerontology and Geriatrics. 2009;52(2):190-6.

[47] Rao AT, Degnan AJ, Levy LM. Genetics of Alzheimer disease. American Journal of Neuroradiology. 2014;35(3): 457-58.

[48] Wenk GL. Neuropathologic changes in Alzheimer's disease. The Journal of Clinical Psychiatry. 2003;64 Suppl 9:7-10.

[49] Hooper NM. Roles of proteolysis and lipid rafts in the processing of the amyloid precursor protein and prion protein. Biochemical Society Transactions. 2005;33(Pt 2): 335-8.

[50] Prakasam A, Muthuswamy A, Ablonczy Z, Greig NH, Fauq A, Rao KJ, et al. Differential accumulation of secreted AbetaPP metabolites in ocular fluids. Journal of Alzheimer's Disease : JAD. 2010;20(4):1243-53.

[51] Padmaraju V, Indi SS, Rao KS. New evidences on TauDNA interactions and relevance to neurodegeneration. Neurochem Int. 2010;57(1):51-7.

[52] Barrio JR, Kepe V, Satyamurthy N, Huang SC, Small G. Amyloid and tau imaging, neuronal losses and function in mild cognitive impairment. The Journal of Nutrition, Health \& Aging. 2008;12(1):61S-5S.

[53] Sambamurti K, Pappolla MA, Jagannatha Rao KS. Value in development of a TAPIR-like mouse monoclonal antibody to Abeta. Journal of Alzheimer's Disease: JAD. 2008;14(2):175-7.

[54] Utsuki T, Yu QS, Davidson D, Chen D, Holloway HW, Brossi A, et al. Identification of novel small molecule inhibitors of amyloid precursor protein synthesis as a route to lower Alzheimer's disease amyloid-beta peptide. The Journal of Pharmacology and Experimental Therapeutics. 2006;318(2):855-62.

[55] Heredia L, Lin R, Vigo FS, Kedikian G, Busciglio J, Lorenzo A. Deposition of amyloid fibrils promotes cellsurface accumulation of amyloid beta precursor protein. Neurobiology of Disease. 2004;16(3):617-29.

[56] Sofi F, Macchi C, Abbate R, Gensini GF, Casini A. Effectiveness of the Mediterranean diet: Can it help delay or prevent Alzheimer's disease? Journal of Alzheimer's disease: JAD. 2010;20(3):795-801.

[57] Solfrizzi V, Capurso C, D'Introno A, Colacicco AM, Santamato A, Ranieri M, et al. Lifestyle-related factors in predementia and dementia syndromes. Expert Review of Neurotherapeutics. 2008;8(1):133-58.

[58] Nehlig A. The neuroprotective effects of cocoa flavanol and its influence on cognitive performance. British Journal of Clinical Pharmacology. 2013;75(3):716-27.

[59] Kawas CH. Medications and diet: Protective factors for AD? Alzheimer Disease and Associated Disorders. 2006;20(3 Suppl 2):S89-96.

[60] Luchsinger JA, Noble JM, Scarmeas N. Diet and Alzheimer's disease. Current Neurology and Neuroscience Reports. 2007;7(5):366-72.

[61] Calon F, Lim GP, Yang F, Morihara T, Teter B, Ubeda O, et al. Docosahexaenoic acid protects from dendritic pathology in an Alzheimer's disease mouse model. Neuron. 2004;43(5):633-45.

[62] Calon F, Cole G. Neuroprotective action of omega3 polyunsaturated fatty acids against neurodegenerative diseases: Evidence from animal studies. Prostaglandins Leukot Essent Fatty Acids. 2007;77(5-6):287-93.
[63] Calon F. Omega-3 Polyunsaturated Fatty Acids in Alzheimer's Disease: Key Questions and Partial Answers. Current Alzheimer Research. 2011;8:470-8.

[64] Vauzour D. Effect of flavonoids on learning, memory and neurocognitive performance: Relevance and potential implications for Alzheimer's disease pathophysiology. Journal of the Science of Food and Agriculture. 2014;94(6):1042-56.

[65] Foltynie T, Kahan J. Parkinson's disease: An update on pathogenesis and treatment. J Neurol. 2013;260(5):143340.

[66] Obeso JA, Rodriguez-Oroz MC, Benitez-Temino B, Blesa FJ, Guridi J, Marin C, et al. Functional organization of the basal ganglia: Therapeutic implications for Parkinson's disease. Movement disorders : Official journal of the Movement Disorder Society. 2008;23 Suppl 3:S548-59.

[67] Aarsland D, Tandberg E, Larsen JP, Cummings JL. Frequency of dementia in parkinson disease. Archives of Neurology. 1996;53(6):538-42.

[68] Korczyn AD, Reichmann H. Dementia with Lewy bodies. Journal of the Neurological Sciences. 2006;248(1-2):3-8.

[69] Walker Z, Allen RL, Shergill S, Katona CL. Neuropsychological performance in Lewy body dementia and Alzheimer's disease. The British Journal of Psychiatry. 1997;170(2):156-8.

[70] McKeith IG, Dickson DW, Lowe J, Emre M, O'Brien JT, Feldman H, et al. Diagnosis and management of dementia with Lewy bodies: Third report of the DLB Consortium. Neurology. 2005;65(12):1863-72.

[71] Boeve BF. Mild cognitive impairment associated with underlying Alzheimer's disease versus Lewy body disease. Parkinsonism \& Related Disorders. 2012;18:S41-S4.

[72] Noyce AJ, Bestwick JP, Silveira-Moriyama L, Hawkes $\mathrm{CH}$, Giovannoni G, Lees AJ, et al. Meta-analysis of early nonmotor features and risk factors for Parkinson disease. Annals of Neurology. 2012;72(6):893-901.

[73] Van Maele-Fabry G, Hoet P, Vilain F, Lison D. Occupational exposure to pesticides and Parkinson's disease: A systematic review and meta-analysis of cohort studies. Environment International. 2012;46:30-43.

[74] de Lau LM, Breteler MM. Epidemiology of Parkinson's disease. The Lancet Neurology. 2006;5(6):525-35.

[75] Costa J, Lunet N, Santos C, Santos J, Vaz-Carneiro A. Caffeine exposure and the risk of Parkinson's disease: A systematic review and meta-analysis of observational studies. Journal of Alzheimer's Disease: JAD. 2010;20 Suppl 1:S221-38.

[76] Connolly BS, Lang AE. Pharmacological treatment of parkinson disease: A review. JAMA. 2014;311(16):167083.

[77] Bronstein JM, Tagliati M, Alterman RL, Lozano AM, Volkmann J, Stefani A, et al. Deep brain stimulation for Parkinson disease: An expert consensus and review of key issues. Arch Neurol. 2011;68(2):165.

[78] Grosso C, Valentão P, Ferreres F, Andrade P. The use of flavonoids in central nervous system disorders. Curr Med Chem. 2013;20(37):4694-719.

[79] Blanchet J, Longpré F, Bureau G, Morissette M, DiPaolo $\mathrm{T}$, Bronchti G, et al. Resveratrol, a red wine polyphenol, protects dopaminergic neurons in MPTP-treated mice. Progress in Neuro-Psychopharmacology and Biological Psychiatry. 2008;32(5):1243-50. 
[80] Prior RL, Cao G, Martin A, Sofic E, McEwen J, O'Brien C, et al. Antioxidant Capacity As Influenced by Total Phenolic and Anthocyanin Content, Maturity, and Variety of Vaccinium Species. Journal of Agricultural and Food Chemistry. 1998;46(7):2686-93.

[81] Goyarzu P, Malin DH, Lau FC, Taglialatela G, Moon WD, Jennings R, et al. Blueberry supplemented diet: Effects on object recognition memory and nuclear factor-kappa B levels in aged rats. Nutritional Neuroscience. 2004;7(2):75-83.

[82] Coultrap SJ, Bickford PC, Browning MD. Blueberryenriched diet ameliorates age-related declines in NMDA receptor-dependent LTP. Age (Dordr). 2008;30(4):263-72.

[83] Tan L, Yang HP, Pang W, Lu H, Hu YD, Li J, et al. Cyanidin3-O-galactoside and Blueberry Extracts Supplementation Improves Spatial Memory and Regulates Hippocampal ERK Expression in Senescence-accelerated Mice. Biomedical and Environmental Sciences : BES. 2014;27(3):186-96.

[84] Joseph JA, Shukitt-Hale B, Denisova NA, Bielinski D, Martin A, McEwen JJ, et al. Reversals of age-related declines in neuronal signal transduction, cognitive, and motor behavioral deficits with blueberry, spinach, or strawberry dietary supplementation. The Journal of neuroscience: The Official Journal of the Society for Neuroscience. 1999;19(18):811421.

[85] Dias AS, Porawski M, Alonso M, Marroni N, Collado PS, Gonzalez-Gallego J. Quercetin decreases oxidative stress, NF-kappaB activation, and iNOS overexpression in liver of streptozotocin-induced diabetic rats. The Journal of Nutrition. 2005;135(10):2299-304.

[86] Martinez-Florez S, Gutierrez-Fernandez B, SanchezCampos S, Gonzalez-Gallego J, Tunon MJ. Quercetin attenuates nuclear factor-kappaB activation and nitric oxide production in interleukin-1beta-activated rat hepatocytes. The Journal of Nutrition. 2005;135(6):1359-65.

[87] Joseph JA, Shukitt-Hale B, Denisova NA, Prior RL, Cao G, Martin A, et al. Long-term dietary strawberry, spinach, or vitamin E supplementation retards the onset of age-related neuronal signal-transduction and cognitive behavioral deficits. The Journal of neuroscience: The Official Journal of the Society for Neuroscience. 1998;18(19):8047-55.

[88] Shukitt-Hale B, Carey AN, Jenkins D, Rabin BM, Joseph JA. Beneficial effects of fruit extracts on neuronal function and behavior in a rodent model of accelerated aging. Neurobiology of Aging. 2007;28(8):1187-94.

[89] Shukitt-Hale B, Carey A, Simon L, Mark DA, Joseph JA. Effects of Concord grape juice on cognitive and motor deficits in aging. Nutrition. 2006;22(3):295-302.

[90] Shukitt-Hale B, Cheng V, Joseph JA. Effects of blackberries on motor and cognitive function in aged rats. Nutritional Neuroscience. 2009;12(3):135-40.

[91] Shih PH, Chan YC, Liao JW, Wang MF, Yen GC. Antioxidant and cognitive promotion effects of anthocyanin-rich mulberry (Morus atropurpurea L.) on senescenceaccelerated mice and prevention of Alzheimer's disease. The Journal of Nutritional Biochemistry. 2010;21(7):598605.

[92] Vogiatzoglou A, Mulligan AA, Luben RN, Lentjes MA, Heiss C, Kelm M, et al. Assessment of the dietary intake of total flavan-3-ols, monomeric flavan-3-ols, proanthocyanidins and theaflavins in the European Union. The British Journal of Nutrition. 2013:1-11.
[93] Asha Devi S, Sagar Chandrasekar BK, Manjula KR, Ishii N. Grape seed proanthocyanidin lowers brain oxidative stress in adult and middle-aged rats. Experimental Gerontology. 2011;46(11):958-64.

[94] Balu M, Sangeetha P, Murali G, Panneerselvam C. Agerelated oxidative protein damages in central nervous system of rats: Modulatory role of grape seed extract. International journal of developmental neuroscience: The official Journal of the International Society for Developmental Neuroscience. 2005;23(6):501-7.

[95] Devi A, Jolitha AB, Ishii N. Grape seed proanthocyanidin extract (GSPE) and antioxidant defense in the brain of adult rats. Medical science monitor: International Medical Journal of Experimental and Clinical Research. 2006;12(4): BR124-9.

[96] Rendeiro C, Vauzour D, Rattray M, Waffo-Teguo P, Merillon JM, Butler LT, et al. Dietary levels of pure flavonoids improve spatial memory performance and increase hippocampal brain-derived neurotrophic factor. PloS One. 2013;8(5):e63535.

[97] van Praag H, Lucero MJ, Yeo GW, Stecker K, Heivand $\mathrm{N}$, Zhao C, et al. Plant-derived flavanol (-)epicatechin enhances angiogenesis and retention of spatial memory in mice. The Journal of neuroscience: The Official Journal of the Society for Neuroscience. 2007;27(22):5869-78.

[98] Schroeter H, Bahia P, Spencer JP, Sheppard O, Rattray M, Cadenas E, et al. (-)Epicatechin stimulates ERK-dependent cyclic AMP response element activity and up-regulates GluR2 in cortical neurons. Journal of Neurochemistry. 2007;101(6):1596-606.

[99] Spencer JP, Schroeter H, Kuhnle G, Srai SK, Tyrrell $\mathrm{RM}$, Hahn $\mathrm{U}$, et al. Epicatechin and its in vivo metabolite, 3'-O-methyl epicatechin, protect human fibroblasts from oxidative-stress-induced cell death involving caspase3 activation. The Biochemical Journal. 2001;354(Pt 3): 493-500.

[100] Huang Q, Wu LJ, Tashiro S, Gao HY, Onodera S, Ikejima T. (+)-Catechin, an ingredient of green tea, protects murine microglia from oxidative stress-induced DNA damage and cell cycle arrest. Journal of Pharmacological Sciences. 2005;98(1):16-24.

[101] Vafeiadou K, Vauzour D, Lee HY, Rodriguez-Mateos A, Williams RJ, Spencer JP. The citrus flavanone naringenin inhibits inflammatory signalling in glial cells and protects against neuroinflammatory injury. Archives of Biochemistry and Biophysics. 2009;484(1):100-9.

[102] Wang J, Varghese M, Ono K, Yamada M, Levine S, Tzavaras N, et al. Cocoa Extracts Reduce Oligomerization of Amyloid- $\beta$ : Implications for Cognitive Improvement in Alzheimer's Disease. Journal of Alzheimer's Disease. 2014;41(2):643-50.

[103] Cuevas E, Limón D, Pérez-Severiano F, Díaz A, Ortega L, Zenteno E, et al. Antioxidant effects of Epicatechin on the hippocampal toxicity caused by Amyloid-beta 25-35 in rats. European Journal of Pharmacology. 2009;616(1-3): 122-7.

[104] Ejaz Ahmed M, Khan MM, Javed H, Vaibhav K, Khan A, Tabassum R, et al. Amelioration of cognitive impairment and neurodegeneration by catechin hydrate in rat model of streptozotocin-induced experimental dementia of Alzheimer's type. Neurochemistry International. 2013;62(4):492-501. 
[105] Desideri G, Kwik-Uribe C, Grassi D, Necozione S, Ghiadoni L, Mastroiacovo D, et al. Benefits in Cognitive Function, Blood Pressure, and Insulin Resistance Through Cocoa Flavanol Consumption in Elderly Subjects With Mild Cognitive Impairment: The Cocoa, Cognition, and Aging (CoCoA) Study. Hypertension. 2012;60(3):794-801.

[106] Ruan H, Yang Y, Zhu X, Wang X, Chen R. Neuroprotective effects of $( \pm)$-catechin against 1-methyl-4-phenyl-1,2,3,6tetrahydropyridine (MPTP)-induced dopaminergic neurotoxicity in mice. Neuroscience Letters. 2009;450(2):152-7.

[107] Ruan H-1, Yang Y, Zhu X-n, Wang X-1, Chen R-z. Similar potency of catechin and its enantiomers in alleviating 1-methyl-4-phenylpyridinium ion cytotoxicity in SH-SY5Y cells. Journal of Pharmacy and Pharmacology. 2011;63(9):1169-74.

[108] Teixeira MDA, Souza CM, Menezes APF, Carmo MRS, Fonteles AA, Gurgel JP, et al. Catechin attenuates behavioral neurotoxicity induced by $6-$ OHDA in rats. Pharmacology Biochemistry and Behavior. 2013;110(0):1-7.

[109] Del Rio D, Costa LG, Lean ME, Crozier A. Polyphenols and health: What compounds are involved? Nutrition, metabolism, and cardiovascular diseases: NMCD. 2010; 20(1):1-6.

[110] Wu X, Cao G, Prior RL. Absorption and metabolism of anthocyanins in elderly women after consumption of elderberry or blueberry. The Journal of Nutrition. 2002;132(7):1865-71.

[111] Barros D, Amaral OB, Izquierdo I, Geracitano L, do Carmo Bassols Raseira M, Henriques AT, et al. Behavioral and genoprotective effects of Vaccinium berries intake in mice. Pharmacology, Biochemistry, and Behavior. 2006;84(2):229-34.

[112] Cho J, Kang JS, Long PH, Jing J, Back Y, Chung KS. Antioxidant and memory enhancing effects of purple sweet potato anthocyanin and cordyceps mushroom extract. Archives of Pharmacal Research. 2003;26(10):821-5.

[113] Ramirez MR, Izquierdo I, do Carmo Bassols Raseira M, Zuanazzi JA, Barros D, Henriques AT. Effect of lyophilised Vaccinium berries on memory, anxiety and locomotion in adult rats. Pharmacological research: The Official Journal of the Italian Pharmacological Society. 2005;52(6):457-62.

[114] Shan Q, Lu J, Zheng Y, Li J, Zhou Z, Hu B, et al. Purple sweet potato color ameliorates cognition deficits and attenuates oxidative damage and inflammation in aging mouse brain induced by d-galactose. Journal of Biomedicine \& Biotechnology. 2009;2009:564737.

[115] Papandreou MA, Dimakopoulou A, Linardaki ZI, Cordopatis P, Klimis-Zacas D, Margarity M, et al. Effect of a polyphenol-rich wild blueberry extract on cognitive performance of mice, brain antioxidant markers and acetylcholinesterase activity. Behavioural Brain Research. 2009;198(2):352-8.

[116] Rendeiro C, Vauzour D, Kean RJ, Butler LT, Rattray M, Spencer JP, et al. Blueberry supplementation induces spatial memory improvements and region-specific regulation of hippocampal BDNF mRNA expression in young rats. Psychopharmacology. 2012;223(3):319-30.

[117] Rendeiro C, Foley A, Lau VC, Ring R, Rodriguez-Mateos A, Vauzour D, et al. A role for hippocampal PSA-NCAM and NMDA-NR2B receptor function in flavonoid-induced spatial memory improvements in young rats. Neuropharmacology. 2013;79C:335-44.
[118] Lau FC, Bielinski DF, Joseph JA. Inhibitory effects of blueberry extract on the production of inflammatory mediators in lipopolysaccharide-activated BV2 microglia. Journal of Neuroscience Research. 2007;85(5):1010-7.

[119] Tarozzi A, Morroni F, Merlicco A, Bolondi C, Teti G, Falconi M, et al. Neuroprotective effects of cyanidin 3-O-glucopyranoside on amyloid beta (25-35) oligomerinduced toxicity. Neuroscience Letters. 2010;473(2):72-6.

[120] Hung T-C, Chang T-T, Fan M-J, Lee C-C, Chen CY-C. In Silico Insight into Potent of Anthocyanin Regulation of FKBP52 to Prevent Alzheimer's Disease. Evidence-Based Complementary and Alternative Medicine. 2014;2014:20.

[121] Cao W, Konsolaki M. FKBP immunophilins and Alzheimer's disease: A chaperoned affair. J Biosci. 2011; 36(3):493-8.

[122] Gutierres JM, Carvalho FB, Schetinger MRC, Marisco $\mathrm{P}$, Agostinho $\mathrm{P}$, Rodrigues $\mathrm{M}$, et al. Anthocyanins restore behavioral and biochemical changes caused by streptozotocin-induced sporadic dementia of Alzheimer's type. Life Sciences. 2014;96(1-2):7-17.

[123] Gutierres JM, Carvalho FB, Schetinger MRC, Rodrigues MV, Schmatz R, Pimentel VC, et al. Protective effects of anthocyanins on the ectonucleotidase activity in the impairment of memory induced by scopolamine in adult rats. Life Sciences. 2012;91(23-24):1221-8.

[124] Strathearn KE, Yousef GG, Grace MH, Roy SL, Tambe MA, Ferruzzi MG, et al. Neuroprotective effects of anthocyaninand proanthocyanidin-rich extracts in cellular models of Parkinson's disease. Brain Research. 2014;1555(0): 60-77.

[125] Dreiseitel A, Korte G, Schreier P, Oehme A, Locher S, Domani $\mathrm{M}$, et al. Berry anthocyanins and their aglycons inhibit monoamine oxidases A and B. Pharmacological Research. 2009;59(5):306-11.

[126] Baur JA, Sinclair DA. Therapeutic potential of resveratrol: The in vivo evidence. Nature Reviews Drug Discovery. 2006;5(6):493-506.

[127] Kris-Etherton PM, Hecker KD, Bonanome A, Coval SM, Binkoski AE, Hilpert KF, et al. Bioactive compounds in foods: Their role in the prevention of cardiovascular disease and cancer. The American Journal of Medicine. 2002;113 Suppl 9B:71S-88S.

[128] Athar M, Back JH, Tang X, Kim KH, Kopelovich L, Bickers DR, et al. Resveratrol: A review of preclinical studies for human cancer prevention. Toxicology and Applied Pharmacology. 2007;224(3):274-83.

[129] Shankar S, Singh G, Srivastava RK. Chemoprevention by resveratrol: Molecular mechanisms and therapeutic potential. Frontiers in Bioscience: A Journal and Virtual Library. 2007;12:4839-54.

[130] King RE, Kent KD, Bomser JA. Resveratrol reduces oxidation and proliferation of human retinal pigment epithelial cells via extracellular signal-regulated kinase inhibition. Chemico-Biological Interactions. 2005;151(2):143-9.

[131] Abraham J, Johnson RW. Consuming a diet supplemented with resveratrol reduced infection-related neuroinflammation and deficits in working memory in aged mice. Rejuvenation Research. 2009;12(6):445-53.

[132] Dal-Pan A, Pifferi F, Marchal J, Picq JL, Aujard F. Cognitive performances are selectively enhanced during chronic caloric restriction or resveratrol supplementation in a primate. PloS One. 2011;6(1):e16581. 
[133] Howitz KT, Bitterman KJ, Cohen HY, Lamming DW, Lavu S, Wood JG, et al. Small molecule activators of sirtuins extend Saccharomyces cerevisiae lifespan. Nature. 2003;425(6954):191-6.

[134] Lagouge M, Argmann C, Gerhart-Hines Z, Meziane H, Lerin C, Daussin F, et al. Resveratrol improves mitochondrial function and protects against metabolic disease by activating SIRT1 and PGC-1alpha. Cell. 2006;127(6):110922.

[135] Zang M, Xu S, Maitland-Toolan KA, Zuccollo A, Hou X, Jiang B, et al. Polyphenols stimulate AMP-activated protein kinase, lower lipids, and inhibit accelerated atherosclerosis in diabetic LDL receptor-deficient mice. Diabetes. 2006;55(8):2180-91.

[136] Csiszar A, Labinskyy N, Pinto JT, Ballabh P, Zhang $\mathrm{H}$, Losonczy $\mathrm{G}$, et al. Resveratrol induces mitochondrial biogenesis in endothelial cells. American Journal of Physiology Heart and Circulatory Physiology. 2009;297(1): H13-20.

[137] Gracia-Sancho J, Villarreal G, Jr., Zhang Y, Garcia-Cardena G. Activation of SIRT1 by resveratrol induces KLF2 expression conferring an endothelial vasoprotective phenotype. Cardiovascular Research. 2010;85(3):514-9.

[138] Picard F, Kurtev M, Chung N, Topark-Ngarm A, Senawong T, Machado De Oliveira R, et al. Sirt1 promotes fat mobilization in white adipocytes by repressing PPAR-gamma. Nature. 2004;429(6993):771-6.

[139] Feige JN, Lagouge M, Canto C, Strehle A, Houten SM, Milne JC, et al. Specific SIRT1 activation mimics low energy levels and protects against diet-induced metabolic disorders by enhancing fat oxidation. Cell Metabolism. 2008;8(5):347-58.

[140] Bordone L, Cohen D, Robinson A, Motta MC, van Veen E, Czopik A, et al. SIRT1 transgenic mice show phenotypes resembling calorie restriction. Aging Cell. 2007;6(6):75967.

[141] Banks AS, Kon N, Knight C, Matsumoto M, GutierrezJuarez R, Rossetti L, et al. SirT1 gain of function increases energy efficiency and prevents diabetes in mice. Cell Metabolism. 2008;8(4):333-41.

[142] Pfluger PT, Herranz D, Velasco-Miguel S, Serrano M, Tschop MH. Sirt1 protects against high-fat diet-induced metabolic damage. Proceedings of the National Academy of Sciences of the United States of America. 2008;105(28): 9793-8.

[143] Pacholec M, Bleasdale JE, Chrunyk B, Cunningham D, Flynn D, Garofalo RS, et al. SRT1720, SRT2183, SRT1460, and resveratrol are not direct activators of SIRT1. The Journal of Biological Chemistry. 2010;285(11):8340-51.

[144] Dai H, Kustigian L, Carney D, Case A, Considine T, Hubbard BP, et al. SIRT1 activation by small molecules: Kinetic and biophysical evidence for direct interaction of enzyme and activator. The Journal of Biological Chemistry. 2010;285(43):32695-703.

[145] Chan AY, Dolinsky VW, Soltys CL, Viollet B, Baksh S, Light PE, et al. Resveratrol inhibits cardiac hypertrophy via AMP-activated protein kinase and Akt. The Journal of Biological Chemistry. 2008;283(35):24194-201.

[146] Cao Z, Fang J, Xia C, Shi X, Jiang BH. trans-3,4,5'Trihydroxystibene inhibits hypoxia-inducible factor 1alpha and vascular endothelial growth factor expression in human ovarian cancer cells. Clinical Cancer Research: An Official
Journal of the American Association for Cancer Research. 2004;10(15):5253-63.

[147] Brito PM, Devillard R, Negre-Salvayre A, Almeida LM, Dinis TC, Salvayre R, et al. Resveratrol inhibits the mTOR mitogenic signaling evoked by oxidized LDL in smooth muscle cells. Atherosclerosis. 2009;205(1):126-34.

[148] Frojdo S, Cozzone D, Vidal H, Pirola L. Resveratrol is a class IA phosphoinositide 3-kinase inhibitor. The Biochemical Journal. 2007;406(3):511-8.

[149] Haider UG, Sorescu D, Griendling KK, Vollmar AM, Dirsch VM. Resveratrol suppresses angiotensin II-induced Akt/protein kinase B and p70 S6 kinase phosphorylation and subsequent hypertrophy in rat aortic smooth muscle cells. Molecular Pharmacology. 2002;62(4):772-7.

[150] Medvedik O, Lamming DW, Kim KD, Sinclair DA. MSN2 and MSN4 link calorie restriction and TOR to sirtuinmediated lifespan extension in Saccharomyces cerevisiae. PLoS Biology. 2007;5(10):e261.

[151] Blagosklonny MV. An anti-aging drug today: From senescence-promoting genes to anti-aging pill. Drug Discovery Today. 2007;12(5-6):218-24.

[152] Han YS, Bastianetto S, Dumont Y, Quirion R. Specific plasma membrane binding sites for polyphenols, including resveratrol, in the rat brain. The Journal of Pharmacology and Experimental Therapeutics. 2006;318(1):238-45.

[153] Simmons DL, Botting RM, Hla T. Cyclooxygenase isozymes: The biology of prostaglandin synthesis and inhibition. Pharmacological Reviews. 2004;56(3):387-437.

[154] Khanduja KL, Bhardwaj A, Kaushik G. Resveratrol inhibits $\mathrm{N}$-nitrosodiethylamine-induced ornithine decarboxylase and cyclooxygenase in mice. Journal of Nutritional Science and Vitaminology. 2004;50(1):61-5.

[155] Aziz MH, Afaq F, Ahmad N. Prevention of ultraviolet-B radiation damage by resveratrol in mouse skin is mediated via modulation in survivin. Photochemistry and Photobiology. 2005;81(1):25-31.

[156] Afaq F, Adhami VM, Ahmad N. Prevention of short-term ultraviolet $B$ radiation-mediated damages by resveratrol in SKH-1 hairless mice. Toxicology and Applied Pharmacology. 2003;186(1):28-37.

[157] Shigematsu S, Ishida S, Hara M, Takahashi N, Yoshimatsu H, Sakata T, et al. Resveratrol, a red wine constituent polyphenol, prevents superoxide-dependent inflammatory responses induced by ischemia/reperfusion, platelet-activating factor, or oxidants. Free Radical Biology \& Medicine. 2003;34(7):810-7.

[158] Manna SK, Mukhopadhyay A, Aggarwal BB. Resveratrol suppresses TNF-induced activation of nuclear transcription factors NF-kappa B, activator protein-1, and apoptosis: Potential role of reactive oxygen intermediates and lipid peroxidation. Journal of Immunology. 2000;164(12):650919.

[159] Holmes-McNary M, Baldwin AS, Jr. Chemopreventive properties of trans-resveratrol are associated with inhibition of activation of the IkappaB kinase. Cancer Research. 2000;60(13):3477-83.

[160] Yeung F, Hoberg JE, Ramsey CS, Keller MD, Jones DR, Frye RA, et al. Modulation of NF-kappaB-dependent transcription and cell survival by the SIRT1 deacetylase. The EMBO Journal. 2004;23(12):2369-80.

[161] Chen G, Shan W, Wu Y, Ren L, Dong J, Ji Z. Synthesis and anti-inflammatory activity of resveratrol analogs. 
Chemical \& Pharmaceutical Bulletin. 2005;53(12):158790.

[162] Adler AS, Sinha S, Kawahara TL, Zhang JY, Segal E, Chang HY. Motif module map reveals enforcement of aging by continual NF-kappaB activity. Genes \& Development. 2007;21(24):3244-57.

[163] Adler AS, Kawahara TL, Segal E, Chang HY. Reversal of aging by NFkappaB blockade. Cell Cycle. 2008;7(5):556-9.

[164] Rotondo S, Rajtar G, Manarini S, Celardo A, Rotillo D, de Gaetano G, et al. Effect of trans-resveratrol, a natural polyphenolic compound, on human polymorphonuclear leukocyte function. British Journal of Pharmacology. 1998;123(8):1691-9.

[165] Jang DS, Kang BS, Ryu SY, Chang IM, Min KR, Kim Y. Inhibitory effects of resveratrol analogs on unopsonized zymosan-induced oxygen radical production. Biochemical Pharmacology. 1999;57(6):705-12.

[166] Surh YJ, Hurh YJ, Kang JY, Lee E, Kong G, Lee SJ. Resveratrol, an antioxidant present in red wine, induces apoptosis in human promyelocytic leukemia (HL-60) cells. Cancer Letters. 1999;140(1-2):1-10.

[167] Martinez J, Moreno JJ. Effect of resveratrol, a natural polyphenolic compound, on reactive oxygen species and prostaglandin production. Biochemical Pharmacology. 2000;59(7):865-70.

[168] Moreno JJ. Resveratrol modulates arachidonic acid release, prostaglandin synthesis, and 3T6 fibroblast growth. The Journal of Pharmacology and Experimental Therapeutics. 2000;294(1):333-8.

[169] Mizutani K, Ikeda K, Kawai Y, Yamori Y. Protective effect of resveratrol on oxidative damage in male and female stroke-prone spontaneously hypertensive rats. Clinical and Experimental Pharmacology \& Physiology. 2001;28(12):55-9.

[170] Floreani M, Napoli E, Quintieri L, Palatini P. Oral administration of trans-resveratrol to guinea pigs increases cardiac DT-diaphorase and catalase activities, and protects isolated atria from menadione toxicity. Life Sciences. 2003;72(24):2741-50.

[171] Robb EL, Winkelmolen L, Visanji N, Brotchie J, Stuart JA. Dietary resveratrol administration increases MnSOD expression and activity in mouse brain. Biochemical and Biophysical Research Communications. 2008;372(1): 254-9.

[172] Chu LM, Lassaletta AD, Robich MP, Sellke FW. Resveratrol in the prevention and treatment of coronary artery disease. Current Atherosclerosis Reports. 2011;13(6): 439-46.

[173] Sakata Y, Zhuang H, Kwansa H, Koehler RC, Dore S. Resveratrol protects against experimental stroke: Putative neuroprotective role of heme oxygenase 1. Experimental Neurology. 2010;224(1):325-9.

[174] Corder R, Crozier A, Kroon PA. Drinking your health? It's too early to say. Nature. 2003;426(6963):119.

[175] Rimando AM, Cuendet M, Desmarchelier C, Mehta RG, Pezzuto JM, Duke SO. Cancer chemopreventive and antioxidant activities of pterostilbene, a naturally occurring analogue of resveratrol. Journal of Agricultural and Food Chemistry. 2002;50(12):3453-7.

[176] Estrela JM, Ortega A, Mena S, Rodriguez ML, Asensi M. Pterostilbene: Biomedical applications. Critical Reviews in Clinical Laboratory Sciences. 2013;50(3):65-78.
[177] Aiyer HS, Warri AM, Woode DR, Hilakivi-Clarke L, Clarke R. Influence of berry polyphenols on receptor signaling and cell-death pathways: Implications for breast cancer prevention. Journal of Agricultural and Food Chemistry. 2012;60(23):5693-708.

[178] Adrian M, Jeandet P, Douillet-Breuil AC, Tesson L, Bessis R. Stilbene content of mature Vitis vinifera berries in response to UV-C elicitation. Journal of Agricultural and Food Chemistry. 2000;48(12):6103-5.

[179] Joseph JA, Fisher DR, Cheng V, Rimando AM, ShukittHale B. Cellular and behavioral effects of stilbene resveratrol analogues: Implications for reducing the deleterious effects of aging. Journal of Agricultural and Food Chemistry. 2008;56(22):10544-51.

[180] Chang J, Rimando A, Pallas M, Camins A, Porquet D, Reeves J, et al. Low-dose pterostilbene, but not resveratrol, is a potent neuromodulator in aging and Alzheimer's disease. Neurobiology of Aging. 2012;33(9):2062-71.

[181] Ramassamy C. Emerging role of polyphenolic compounds in the treatment of neurodegenerative diseases: A review of their intracellular targets. European Journal of Pharmacology. 2006;545(1):51-64.

[182] Kim D, Nguyen MD, Dobbin MM, Fischer A, Sananbenesi F, Rodgers JT, et al. SIRT1 deacetylase protects against neurodegeneration in models for Alzheimer's disease and amyotrophic lateral sclerosis. The EMBO Journal. 2007;26(13):3169-79.

[183] Karuppagounder SS, Pinto JT, Xu H, Chen H-L, Beal MF, Gibson GE. Dietary supplementation with resveratrol reduces plaque pathology in a transgenic model of Alzheimer's disease. Neurochemistry International. 2009;54(2):111-8.

[184] Marambaud P, Zhao H, Davies P. Resveratrol Promotes Clearance of Alzheimer's Disease Amyloid-beta Peptides. Journal of Biological Chemistry. 2005;280(45):37377-82.

[185] Wang J, Santa-Maria I, Ho L, Ksiezak-Reding H, Ono K, Teplow DB, et al. Grape Derived Polyphenols Attenuate Tau Neuropathology in a Mouse Model of Alzheimer's Disease. Journal of Alzheimer's Disease. 2010;22(2): 653-61.

[186] Wang J, Bi W, Cheng A, Freire D, Vempati P, Zhao $\mathrm{W}$, et al. Targeting multiple pathogenic mechanisms with polyphenols for the treatment of Alzheimer's disease-experimental approach and therapeutic implications. Frontiers in Aging Neuroscience. 2014;6(42):1-10.

[187] Dal-Pan A, Julien C, Pierrisnard C, Tremblay C, Calon F. Resveratrol and, to a lesser extent, docosahexaenoic acid, induce disease-modifying effects in old 3xTg-AD mice. 24th Alzheimer's Association International Conference (Vancouver, Canada) 2014.

[188] Okawara M, Katsuki H, Kurimoto E, Shibata H, Kume T, Akaike A. Resveratrol protects dopaminergic neurons in midbrain slice culture from multiple insults. Biochemical Pharmacology. 2007;73(4):550-60.

[189] Lu K-T, Ko M-C, Chen B-Y, Huang J-C, Hsieh C-W, Lee M-C, et al. Neuroprotective Effects of Resveratrol on MPTP-Induced Neuron Loss Mediated by Free Radical Scavenging. Journal of Agricultural and Food Chemistry. 2008;56(16):6910-3.

[190] Albani D, Polito L, Batelli S, De Mauro S, Fracasso C, Martelli G, et al. The SIRT1 activator resveratrol protects SK-N-BE cells from oxidative stress and against toxicity 
caused by $\alpha$-synuclein or amyloid- $\beta$ (1-42) peptide. Journal of Neurochemistry. 2009;110(5):1445-56.

[191] Virmani A, Pinto L, Binienda Z, Ali S. Food, Nutrigenomics, and Neurodegeneration-Neuroprotection by What You Eat! Molecular Neurobiology. 2013;48:353-62.

[192] Abd El Mohsen MM, Kuhnle G, Rechner AR, Schroeter H, Rose S, Jenner P, et al. Uptake and metabolism of epicatechin and its access to the brain after oral ingestion. Free Radical Biology \& Medicine. 2002;33(12):1693-702.

[193] Prasain JK, Peng N, Dai Y, Moore R, Arabshahi A, Wilson $\mathrm{L}$, et al. Liquid chromatography tandem mass spectrometry identification of proanthocyanidins in rat plasma after oral administration of grape seed extract. Phytomedicine: International Journal of Phytotherapy and Phytopharmacology. 2009;16(2-3):233-43.

[194] Ferruzzi MG, Lobo JK, Janle EM, Cooper B, Simon JE, $\mathrm{Wu} \mathrm{QL}$, et al. Bioavailability of gallic acid and catechins from grape seed polyphenol extract is improved by repeated dosing in rats: Implications for treatment in Alzheimer's disease. Journal of Alzheimer's Disease: JAD. 2009;18(1):113-24.

[195] Youdim KA, Qaiser MZ, Begley DJ, Rice-Evans CA, Abbott NJ. Flavonoid permeability across an in situ model of the blood-brain barrier. Free Radical Biology \& Medicine. 2004;36(5):592-604.

[196] Passamonti S, Vrhovsek U, Vanzo A, Mattivi F. Fast access of some grape pigments to the brain. Journal of Agricultural and Food Chemistry. 2005;53(18):7029-34.

[197] Kalt W, Blumberg JB, McDonald JE, Vinqvist-Tymchuk MR, Fillmore SA, Graf BA, et al. Identification of anthocyanins in the liver, eye, and brain of blueberry-fed pigs. Journal of Agricultural and Food Chemistry. 2008;56(3): 705-12.

[198] Milbury PE, Kalt W. Xenobiotic metabolism and berry flavonoid transport across the blood-brain barrier. Journal of Agricultural and Food Chemistry. 2010;58(7): 3950-6.

[199] El Mohsen MA, Marks J, Kuhnle G, Moore K, Debnam E, Kaila Srai S, et al. Absorption, tissue distribution and excretion of pelargonidin and its metabolites following oral administration to rats. The British Journal of Nutrition. 2006;95(1):51-8.
[200] Borges G, Roowi S, Rouanet JM, Duthie GG, Lean ME, Crozier A. The bioavailability of raspberry anthocyanins and ellagitannins in rats. Molecular Nutrition \& Food Research. 2007;51(6):714-25.

[201] Asensi M, Medina I, Ortega A, Carretero J, Bano MC, Obrador E, et al. Inhibition of cancer growth by resveratrol is related to its low bioavailability. Free Radical Biology \& Medicine. 2002;33(3):387-98.

[202] Wang Q, Xu J, Rottinghaus GE, Simonyi A, Lubahn D, Sun GY, et al. Resveratrol protects against global cerebral ischemic injury in gerbils. Brain Research. 2002;958(2): 439-47.

[203] Abd El-Mohsen M, Bayele H, Kuhnle G, Gibson G, Debnam E, Kaila Srai S, et al. Distribution of $[3 \mathrm{H}]$ transresveratrol in rat tissues following oral administration. The British Journal of Nutrition. 2006;96(1):62-70.

[204] Juan ME, Maijo M, Planas JM. Quantification of transresveratrol and its metabolites in rat plasma and tissues by HPLC. Journal of Pharmaceutical and Biomedical Analysis. 2010;51(2):391-8.

[205] Youdim KA, Shukitt-Hale B, Joseph JA. Flavonoids and the brain: Interactions at the blood-brain barrier and their physiological effects on the central nervous system. Free Radical Biology \& Medicine. 2004;37(11):1683-93.

[206] Stefkova J, Poledne R, Hubacek JA. ATP-binding cassette $(\mathrm{ABC})$ transporters in human metabolism and diseases. Physiological Research/Academia Scientiarum Bohemoslovaca. 2004;53(3):235-43.

[207] Brand W, Schutte ME, Williamson G, van Zanden JJ, Cnubben NH, Groten JP, et al. Flavonoid-mediated inhibition of intestinal $\mathrm{ABC}$ transporters may affect the oral bioavailability of drugs, food-borne toxic compounds and bioactive ingredients. Biomedicine \& Pharmacotherapy=Biomedecine \& Pharmacotherapie. 2006;60(9):50819.

[208] Scheepens A, Tan K, Paxton JW. Improving the oral bioavailability of beneficial polyphenols through designed synergies. Genes \& Nutrition. 2010;5(1):75-87.

[209] Spencer JP, Abd El Mohsen MM, Minihane AM, Mathers JC. Biomarkers of the intake of dietary polyphenols: Strengths, limitations and application in nutrition research. The British Journal of Nutrition. 2008;99(1):12-22. 